\section{Principled man in unprincipled times}

\author{
Martin J. Klein
}

The Dilemmas of an Upright Man: Max Planck as Spokesman for German Science.

By John L. Heilbron. University of California Press: 1986. Pp.238. \$16.95, £14.50.

Max Planck (1858-1947) exemplified the traditional values of the world in which he grew up, the world of a conservative, cultured German family of pastors, scholars and jurists. The very model of a classical physicist, he "embodied with rare completeness", according to Albert Einstein, the "ideal search for truth .... a bond forever uniting scientists of all times and in all places". But his very devotion to the search for absolute scientific truth led Planck inexorably to the quantum of energy with which his name is permanently linked, the symbol of this century's nonclassical physics. His unshakable sense of responsibility led him, equally inexorably, to accept a series of positions of authority in the German academic and scientific establishments. By 1914 he had become the acknowledged spokesman for German physics, a role he could not in conscience relinquish when his country was transformed into the Weimar republic and then entered the dark times that began in 1933. As John Heilbron writes in his preface, Planck's

struggle to come to grips with changing political circumstances, and his efforts to adjust the image of science and civic life that he developed before 1900 to the realities of twentieth-century Germany have the elements of heroic tragedy.

Heilbron's book, the first in English devoted to Planck, is an outstanding piece of work by one of our finest historians of science. Heilbron's earlier writings include an admirable study of Henry Moseley's life and work, a major book on early intellectual and institutional developments in physics, Electricity in the 17th and 18th Centuries, and a series of articles and monographs on a wide range of subjects in the physical science of the past four centuries. Among its other impressive features, his work always shows his mastery of "the bibliographic resourcefulness proper to the historian".

As his title implies, Heilbron's primary concern in this book is Planck's role as spokesman for science rather than the physics he actually did. Heilbron does sketch Planck's development from exclusive devotee of thermodynamics through his gradual acceptance of the need for both atomism and a statistical approach, and he shows how Planck used his hard-won theory of blackbody radiation to determine the first reliable values of the atomic constants. We see Planck, conservative in his stance towards the developing quantum theory, immediately and enthusiastically respond to the special theory of relativity and its

IMAGE
UNAVAILABLE
FOR
COPYRIGHT
REASONS

Max Planck-public silence, private integrity. author. Planck was one of those who brought Einstein to Berlin in 1914, and it was Planck's presence that helped to keep him there: "To be near Planck is a joy", Einstein once wrote.

There is no irony in Heilbron's designation of Planck as an upright man. "Respect for laws, trust in established institutions, observance of duty, and absolute honesty" are listed as "the hallmarks of Planck's character". These were combined with genuine modesty and the clear conscience that came with his responsible adherence to his principles. Not a man for public pronouncements, Planck showed his opposition to academic anti-Semitism preceding the First World War by acting quietly to keep qualified Jewish physicists such as Emil Warburg and Lise Meitner from being denied positions on irrelevant grounds.

By 1914 Planck held a series of major positions in the German Physical Society, the Prussian Academy of Sciences, the Kaiser-Wilhelm-Gesellschaft, and, as war began, as Rector of the University of Berlin. He faced the war with mixed emotions, foreseeing "something great, along with something monstrous". Planck was one of the 93 intellectuals who signed the famous "Appeal to the Cultured Peoples of the World" in October 1914, denying German atrocities in Belgium and expressing the unity of German culture and German arms. Unlike most of his cosigners he soon moderated his position and worked to maintain the possibility of post-war inter-

$\sum$ national reconciliation among scientists. His 1916 open letter to H.A. Lorentz emphasized his

firm conviction that there are domains of intellectual and moral life that lie beyond the struggles of nations, and that honourable cooperation in the cultivation of these international cultural values and, not less, personal respect for citizens of enemy states are indeed compatible with ardent love and energetic work for one's own country.

Few citizens of any belligerent nation have publicly subscribed to such enlightened views in the midst of a modern war.

Planck had to call on all his internal resources to go on with his work after his own losses in the war years: his first son was killed in action and his twin daughters both died in childbirth. Devotion to duty sustained him in this time of personal grief and national upheaval. Unlike many of his conservative colleagues he gave his loyal supporf to a republic whose principles were not his own. Heilbron discusses Planck's staunch support of Einstein when vicious anti-Semitic attacks were directed against both the man and his general relativity, but he stresses Planck's avoidance of public statements that he thought might encourage the politicization of science. We see Planck struggling to help restore normal international relations among scientists despite the severe restrictions imposed by the victorious Allied powers. As if these tasks and his efforts to secure adequate financial support for physicists were not enough for a man approaching his seventieth year, Planck also undertook to defend a causal, realistic philosophy of physics in the new age of quantum mechanics.

The problems Planck dealt with in the Weimar era were minor compared to those he confronted after Hitler took 
power in 1933. As secretary of the Academy and president of the KaiserWilhelm-Gesellschaft, Planck could not avoid dealing with the government. Convinced at first that the Nazi excesses could not last, and that Hitler's call for national revival and unity had much to be said in its favour, Planck was ready to accommodate to the demands of the new regime. At 75 he would have been relieved to give up the burdens of his offices, but he felt responsible to those who counted on his help and trusted his "immensely noble purity".

Planck's hopes for quick return to civilized behaviour in Germany were quickly dashed when his Jewish colleagues were forced out of their positions and many of them left the country. Still reluctant to make public statements, Planck did not protest against the Academy's offensive response to Einstein's resignation. He went on advising his younger colleagues to have patience and stay at their posts. Nevertheless, it was Planck who went directly to Hitler in May 1933 and tried to convince him that his policies were destroying German science. Hitler would make no distinctions, and became so enraged that Planck could only "fall silent and take my leave". His efforts to salvage what could be salvaged, to block (behind the scenes) the irrational behaviour of his fellow Nobel laureates Philipp Lenard and Johannes Stark, both enthusiastic admirers of Hitler since 1924, did have some positive results. More and more frequently, however, he had to compromise his principles and accept the unacceptable.

During the Second World War, now an octogenarian but free of offices at last, Planck continued his public lectures on science and philosophy, using them as a platform for defending the values of science and civilization and for implicit criticisms of the regime. The disasters of the war, and especially the arrest and execution of his son Erwin for complicity in the 1944 attempt to assassinate Hitler, finally broke Planck's spirit. He died in 1947, just short of his ninetieth birthday.

Heilbron's thoughtful book makes it clear that there were no easy answers to the dilemmas Planck faced. Einstein did not forgive Planck for his public silence in 1933, but he had never lived with Planck's responsibilities. One can speculate on what might have happened if Planck had made a different series of decisions, but speculation is only speculation. Planck acted in accordance with his principles and his conscience, though the world crumbling around him had little place for either. Heilbron writes in his preface that Planck's "life is a lesson", but each reader must decide for himself what that lesson is.

Martin J. Klein is Higgins Professor of the History of Physics at Yale University, Box 2036. New Haven, Connecticut 06520, USA.

\section{Matter of utmost gravity}

\author{
Joseph H. Taylor
}

Was Einstein Right? Putting General Relativity to the Test. By Clifford M. Will. Basic Books: 1986. Pp.253. \$18.95.

IN THE centenary year of Albert Einstein's birth, 1979, a number of books appeared which described the man and his science, especially general relativity. Seven years later, Clifford Will has added another to the list - a readable volume detailing the renaissance that has taken place in gravitational physics since a few years after Einstein's death in 1955. Writing for a general audience, Will describes (sometimes with first-hand knowledge, and always with flair) developments of the past quarter-century which provide the underpinnings of our understanding of the gravitational interaction in nature and its apparently inextricable connection with the geometry of the Universe.

The 1960 s, heyday of radio astronomy, dawn of the space age and beginning of the era of atomic clocks, saw for the first time the development of experimental techniques well suited to the high-precision measurement of tiny differences between the predictions of newtonian gravitation theory, general relativity and other "currently viable alternatives". Will tells us of these developments, taking a topical approach. He starts with the reincarnated "Eötvös experiments" arried out in Princeton and the Soviet Union, which verified the equivalence principle to very high precision. Gravitational red-shift tests are described next, with emphasis on the Pound-Rebka-Snider experiments using gamma rays in the Jefferson Tower at Harvard, and the "flying atomic clocks" experiments carried out by Robert Vessot and others a few years later. Together, these tests showed conclusively that a correct theory of gravity must be a metric theory, embodying the concepts of curved space-time.

Subsequent chapters deal with modern experiments measuring the bending of radio waves by the Sun's gravity, the perihelion shift of Mercury by radar ranging techniques, the slowed propagation of signals in the solar gravitational field, extension of the equivalence principle to include the self-gravitational binding energies of the Earth and Moon, the constancy of the gravitational "constant" $G$, and the loss of orbital energy in the binary pulsar system by gravitational radiation. Throughout the narrative, Will sprinkles a trail of personalities and anecdotes. Robert Dicke's name appears frequently: first as the author of a 1961 article in Scientific American which helped to convert the teenaged Clifford Will from a career in architecture, or maybe genetics, to one in physics; later as quintessential experimenter, and co-author of a theory of gravitation to rival Einstein's; later still as a passenger on an airplane bound for Missoula, Montana, on which he was informed by Kenneth Nordvedt, then a total stranger, that the Brans-Dicke theory appeared to be inconsistent with the equivalence principle for strongly selfgravitating bodies.

Irwin Shapiro's discovery of the gravitational propagation delay for electromagnetic waves makes a good story; it includes an image of Shapiro making an eleventh-hour pitch - via long-distance telephone connection from Cambridge,

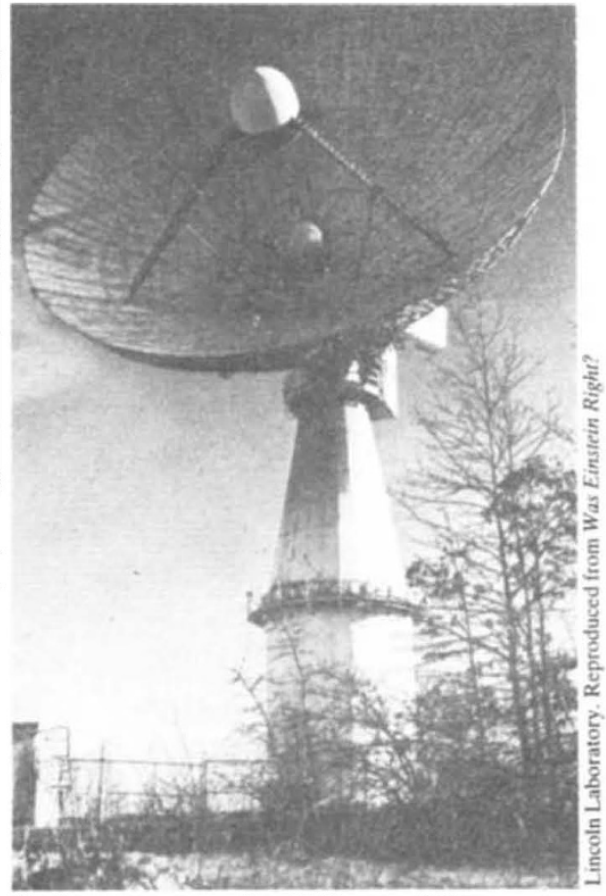

Radar ranger - the Millstone Hill antenna, northern Massachusetts, used by researchers at the Massachusetts Institute of Technology from 1959 for radar echo observations of the planets.

Massachusetts, to the Jet Propulsion Laboratory in California, complete with locally shown viewgraphs, NASA style pleading for inclusion of the time-delay experiment on the forthcoming Viking mission to Mars. The story of the discovery of the Hulse-Taylor binary pulsar is here, too, complete with graphical sketches reproduced from Russell Hulse's laboratory notebook and with the correct inference that graduate student Hulse and assistant professor Taylor were thoroughly astonished by the potential implications of what they had found.

Will has succeeded in what he set out to do, namely to write an interesting and accessible account of recent progress in one field of physics.

Joseph H. Taylor is James S. McDonnell Distinguished University Professor of Physics at Princeton University, Princeton, New Jersey 08544, USA. 